\title{
Antiviral activities of Cholistani plants against common poultry viruses
}

\author{
Shahzad, M.I. ${ }^{1 *}$, Anwar, S. ${ }^{2}$, Ashraf, H. ${ }^{2}$, Manzoor, A. ${ }^{2}$, Naseer, M. ${ }^{2}$, Rani, U. ${ }^{2}$, Aslam, Z. ${ }^{2}$, Saba, N. ${ }^{2}$, \\ Kamran, Z. ${ }^{3}$, Ali, S. ${ }^{4}$, Aslam, J. ${ }^{1}$ and Arshad, M. ${ }^{5}$ \\ ${ }^{1}$ Department of Biochemistry \& Biotechnology. The Islamia University of Bahawalpur, Pakistan \\ ${ }^{2}$ Department of Botany. The Govt Sadiq College Women University, Bahawalpur, Pakistan. Pakistan \\ ${ }^{3}$ University college of Veterinary and Animal Sciences, The Islamia University, Bahawalpur \\ ${ }^{4}$ Govt. poultry farm, Model Town A, Bahawalpur. Pakistan \\ ${ }^{5}$ Department of Biochemistry, College of Veterinary and Animal Sciences, Jhang Campus, UVAS Lahore, \\ Pakistan \\ *Corresponding author e-mail: mirza.imran@iub.edu.pk \\ Received 5 April 2020; received in revised form 17 September 2020; accepted 20 September 2020
}

\begin{abstract}
Herbal medicines are becoming more popular and acceptable day by day due to their effectiveness, limited side effects, and cost-effectiveness. Cholistani plants are reported as a rich source of antibacterial, antifungal, antiprotozoal, antioxidant, and anticancer agents. The current study has evaluated antiviral potential of selected Cholistani plants. The whole plants were collected, ground and used in extract formation with $n$-hexane, ethyl acetate and $n$-butanol. All the extracts were concentrated by using a rotary evaporator and concentrate was finally dissolved in an appropriate vol of the same solvent. All of the extracts were tested for their antiviral potential by using 9-11 days old chick embryonated eggs. Each extract was tested against the Avian Influenza virus H9N2 strain (AIV), New Castle Disease virus Lasoota strain (NDV), Infectious bronchitis virus (IBV) and an Infectious bursal disease virus (IBDV). Hemagglutination test (HA) and Indirect Hemagglutination (IHA) tests were performed for different viruses. The overall order of the antiviral potential of Cholistani plants against viruses was $\mathrm{NDV}>\mathrm{IBV}>\mathrm{IBDV}>\mathrm{AIV}$. In terms of antiviral activity from extracts, the order of activity was $n$-butanol>ethyl acetate $>n$-hexane. The medicinal plants Achyranthes aspera, Neuroda procumbens, Panicum antidotale, Ochthochloa compressa and Suaeda fruticose were very effective against all four poultry viruses through their extracts. The low $\mathrm{IC}_{50}$ values of these extracts confirm the high antiviral potential against these viruses. It is worth to mention that Achyranthes aspera was found positive against IBDV through all its extracts which overcome the problem of unavailability of any known drug against IBDV. In short, the study proved that Cholistani plants are rich source of antiviral agent and their extracts can be used as good source of antiviral drugs both in crude and in purified form.
\end{abstract}

\section{INTRODUCTION}

For thousands of years, medicinal plants are in use to support human health. The medicinal constituents of these plants are not only playing important roles in traditional medicines but also modern medicines (Arunkumar \& Muthuselva, 2009). The drugs obtained from plants are considered relatively safer, cheap, easy to use and with no or limited side effects. The use of herbal medicines is increasing all over the world
(Rasool et al., 2015). The use of plant extracts in food, cosmetics, and pharmaceutical industries shows its public acceptance (Nostro et al., 2000). The trend to use natural products and medicinal plants in the USA and Canada is exponentially growing (Roeder et al., 2015). Several hundred natural products have been isolated for screening and identifying the antiviral activity, and some have been successfully approved for pre-clinical and clinical trials (Kitazato et al., 2007). Cholistani plant Oxystelma 
esculentum (Asclepiadaceae) is a twiner growing in waterlogged areas and used commonly as anti-ulcer and diuretic (Pandya \& Anand, 2013). Haloxylon silicornicum (Amaranthaceous) has values of vegetation (Shafi et al., 2002). Its extracts are also used in the treatment of diabetes and eye disorders. Haloxylon recurvum (Chenopodiaceae) is used externally against insect bites and also acknowledge a good source of fuel (Dagla \& Shekhawat, 2005). Achyranthes asper (Amaranthaceae) is best known for its cardiovascular and spermicidal activities (Srivastava et al., 2011). Solanum surattense (Solanaceae) commonly known as Indian nightshade and has been used for curing fever, cough, asthma, and diabetes (Munuswamy et al., 2013). Salsola bryosoma (Chenopodiaceae) used as fodder, fuel and fire set. This plant is also used in Mauritania for laundering cloth. Neurada procumbens (Neuradaceae) is well known for its common uses (Chen et al., 2004). Panicum antidotale (Graminae) known as bansighass and used to control soil erosion (Arshadullah et al., 2009). Sporo bolusicolados (Poaceae) commonly known as sakham, mainly used as forage (Gulzar \& Khan, 2015). Octhocloa compressa (Poaceae) is used as the source of fodder (Ahmed et al., 2014). Suaeda fruticosa (Amaranthaceae) is shrubby halophyte and resist Reactive Oxygen Species (Samiullah et al., 2012). Several plants are found effective against herpes simplex type I, Avian Influenza strain, and other poultry viruses (Abad et al., 1997; Chollom et al., 2012; Pant et al., 2012; Chen et al., 2014;). A highly effective natural product based antiviral compound against the hepatitis C virus is reported by (Lee $e t$ $a l ., 2016)$. Similarly, Cholistani plants are found effective against the Infectious Bronchitis Virus (IBV) and Infectious Bursal Disease Virus (IBDV) (Aslam et al., 2016).

Poultry viruses are a big cause of economic loss to industry due to their high morbidity and mortality in birds. Viruses like New Castle Disease (NDV), Avian Influenza Virus (AIV) H9N2, Infectious Bronchitis Virus (IBV) and Infectious Bursal Disease Virus (IBDV) are a serious threat to the poultry industry (Aslam et al., 2016). Newcastle disease (ND), caused by virus of family Paramyxoviridae and is one of the most urgent and serious problem of poultry. The NDV LaSota strain is naturally occurring low-virulence strain, has been routinely used as a live vaccine throughout the world (Zhao et al., 2016). Influenza A viruses are members of the Orthomyxoviridae family and contain a segmented, negative-sense RNA genome encoding 10 proteins and a variable number of accessory proteins. Influenza A viruses are commonly characterized by their combinations of surface proteins, haemagglutinin (HA) and neuraminidase (NA), giving rise to a multitude of different subtypes designated like H9N2 (Wu et al., 2014). Infectious bronchitis virus (IBV), which cause one of the major and economically important disease of poultry is commonly known as IB or Muttadi Khansi. Interestingly, it was found that IBV is able to inhibit multiple cellular stress granule signaling pathways, at the same time, its replication also results in the induction of stress granules in certain parts of infected cells (Brownsword et al., 2020). Infectious bursal disease (IBD) is commonly known as Gumboro disease is a very common disease of young chick, caused by IBD virus. Its infection causes loss of B cells approximately 7-10 days post infection. The socio-economic impact of IBDV is worldwide (Vanden Berg et al., 2000).

Every year these viruses are causing great economic loss and affecting the trade of poultry all over the world (Okwor et al., 2011; Aslam et al., 2016; Sae Silva et al., 2016). Extensive poultry farming, dense human population, lack of education, a high risk of infection and poor biosecurity measures are common factors in spread of viral diseases in Southeast Asian, North African and Middle East countries (Premnathan et al., 1992; Giasuddin et al., 2012; Lee et al., 2012; Li et al., 2016). Although extensive vaccination campaigns were introduced to control viral outbreaks but still these diseases are uncontrolled in different parts of the world especially in Pakistan. The phenomenon like genetic drifting/genetic shifting, availability of very few antiviral agents and poor quality of vaccines are other 
factors to avoid control of these diseases (Singh, 2011). Therefore, the demand of new, novel and more effective antiviral agent(s) is increasing. The disease like IBD, there is no known drug is available in the market except crude extracts of medicinal plants (Gupta \& Chaphalkar, 2015; Aslam et al., 2016; Shahzad et al., 2019).

\section{MATERIALS AND METHODS}

\section{Collection of specimens}

Eleven fresh plants including Oxystelma esculentum L.F. (Asclepiadaceae), Haloxylon salicornicum Moq. (Amaranthaceous), Haloxylon recurvum Moq. (Chenopodiaceae), Achyranthes aspera ITIS. (Amaranthaceae), Solanum surattense Linn. (Solanaceae), Salsola baryosma Roem. et Shult (Chenopodiaceae), Neuroda procumbens L. (Neuradaceae), Panicum antidotale Retz. (Poaceae), Sporobolus icolados Nees ex Trin. (Poaceae), Ochthochloa compressa CoL (Poaceae), and Suaeda fruticose auct. non Forsk (Amaranthaceae), were collected from the Cholistan desert and identified by Botanists at Herbarium of the Cholistan Institute of Desert Studies (CIDS), The Islamia University of Bahawalpur, as a whole plant. All the vouchers are available at CIDS, The Islamia University of Bahawalpur. Four poultry viruses were selected for this study, which includes vaccinal strains of New Castle disease virus (NDV) named as LaSota, Avian influenza virus (AIV) H9N2 named as Gallimune Flu H9 M.E from Merial Laboratories Italy. Infectious bronchitis virus (IBV) H120 from IZO S.U.R.L 99/A-25124 Brassica Italy. Infectious bursal disease virus (IBDV) named as DS Gumboro Vac from Dae Sung Microbiological Laboratories, Seoul, South Korea.

\section{Preparation of Plant extracts}

Whole plants were collected, cleaned and dried under the shade at RT for 10-12 days. The dried plants were ground to powder form and powders were kept in airtight containers at RT. Ten gram powder from each plant was taken and dissolved in $100 \mathrm{~mL} n$-hexane,
Ethyl acetate, and $n$-butanol. The methanol extracts of these plants were already tested by author (Aslam et al., 2016; Shahzad et al., 2019). The solutions were kept in airtight containers for $96 \mathrm{~h}$ at constant shaking and subjected to the rotary evaporator $\left(45-50^{\circ} \mathrm{C}\right)$. After evaporating the solvent the solutes were rinsed by methanol and chloroform in conical flasks and allow them to re-evaporate. Finally, the precipitates were weighed and dissolved in each corresponding solvent @ 0.5mg/mL. The extracts were sterilized through syringe filter and stored at $-20^{\circ} \mathrm{C}$ (Joshi, 2013).

\section{Viruses}

The four viruses including Avian Influenza virus H9N2 strain (AIV), New Castle Disease virus Lasoota strain (NDV), Infectious bronchitis virus (IBV) and an Infectious bursal disease virus (IBDV) were used in this study. All the viruses were tested against different extracts through In Ovo antiviral assay.

\section{Inoculation of viruses in chicken egg} Specific pathogen free (SPF) eggs were obtained eggs from the government poultry farm, Model Town A. Bahawalpur. All the above-mentioned viruses were inoculated in the chorioallantoic fluid of 9-11 days old chick embryonated (CE) eggs. The eggs were candled before and after inoculations. The broader ends of eggs were swabbed with $70 \%$ alcohol and transferred into cleaned trays in biosafety cabinet II. The broader ends of eggs were drilled with sterile needle and viral inoculum is injected through sterile 3cc syringe. After inoculation, the hole was sealed with molten wax and eggs were incubated at $37^{\circ} \mathrm{C}$. The eggs were harvested $72 \mathrm{~h}$ post-inoculation (PI) and allantoic fluids were collected and subjected to HA or IHA (in case of IBDV) test to check titer of each virus. This whole procedure was done in biosafety cabinet type II. Serial passages of viruses were done to increase titer before taking antiviral trials from extracts of Cholistani plants (Bajpai \& Chandra, 1990).

\section{Hemagglutination Test (HA)}

The HA test was performed to quantify the titer of viruses except for IBDV (Elizondo- 
Gonzalez et al., 2012). A freshly prepared Alsevier solution was used to collect $5 \mathrm{~mL}$ of chicken blood. The blood was centrifuged at $4000 \mathrm{rpm}$ for $5 \mathrm{~min}$ and supernatant was discarded. The cells were washed with PBS ( $\mathrm{pH}$ 7.4) three times and finally dissolved to make a $1 \%$ solution.). The 96 wells round bottom plates were used in assay. First of all, $50 \mu \mathrm{L}$ PBS solution was added in each well. Then $50 \mu \mathrm{L}$ virus (allantoic fluid) was added in first well and mixed three times and $50 \mu \mathrm{L}$ solution was transferred into $2^{\text {nd }}$ well and mixed and this serial dilution was proceeded up to $11^{\text {th }}$ well. The $12^{\text {th }}$ well was kept as -ve control. The 1\% RBC's solution was added @ $50 \mu \mathrm{L}$ in each well and plates were kept at $37^{\circ} \mathrm{C}$ for $1 \mathrm{hr}$ and the HA activity was noted (OIE, 2012). In the case of AIV H9N2 and NDV the drug amantadine was used as positive control and in case of IBV LiCl used as positive control.

\section{Indirect Hemagglutination (IHA) Test}

This test was performed to quantify IBDV and human blood type "O" was used in it. Three mL blood was taken in a $4 \%$ sodium citrate solution and mixed gently. It was centrifuged at $4000 \mathrm{rpm}$ for $5 \mathrm{~min}$ and the supernatant was removed. The cells were dissolved in $10 \mathrm{~mL}$ PBS $(\mathrm{pH} \mathrm{7.4)}$ and centrifuged again at $4000 \mathrm{rpm}$ for $5 \mathrm{~min}$. This step was repeated three times. After washing, the cells were sensitized by mixing with an equal vol of IBDV and two vol of PBS (pH 7.4). The contents were mixed gently and incubated at $37^{\circ} \mathrm{C}$ for 45 min. After incubation, the cells were centrifuged at $4000 \mathrm{rpm}$ and the supernatant was removed and washed with PBS (pH 7.4) again and finally, diluted to make $1 \%$ suspension (Okwor et al., 2011). Later, the standard HA test was performed by using these sensitized cells (Hussain \& Gorsi, 2004). No positive control used for IBDV because no known drug is available.

\section{In Ovo Analysis}

The filter sterilized plant extracts were mixed with equal vol. of viral inoculums and injected in 9-11 days old CEE (Rajbhandari, 2001). Autoclave distilled water was used in case of negative control and virus without any plant extracts were used in case of virus control. All the inoculated eggs were harvested $72 \mathrm{~h}$ PI and subjected to HA or IHA. Any change in the case of button formation in comparison to virus control was noted. $\mathrm{IC}_{50}$ of each positive extract was calculated by making serial dilutions of extracts and challenged against viruses.

\section{Calculation of IC50}

IC50 was calculated by testing serially diluted drugs against each virus. Easy fit software was used to calculate dose and time dependent curves by linear regression and IC50 value presented the results in Table 1.

\section{Statistical Analysis}

Data showed mean and standard deviations. Statistical analysis was performed using one-way ANOVA and a p-value considered a significant difference at $\mathrm{P}<0.05$ (Steel $e t$ al., 1997).

\section{RESULTS}

\section{Cultivation of Viruses}

Viruses were cultivated in embryonated eggs (CE) to achieve certain titer before the start of antiviral studies. In the case of New Castle Disease (NDV), the HA titer 2048 was achieved after the $6^{\text {th }}$ passage. In the case of the Avian Influenza Virus (AIV) and Infectious Bronchitis Virus (IBV), the HA titers 2048 were achieved after the $9^{\text {th }}$ passage. Similarly, in the case of Infectious Bursal Disease Virus (IBDV), the IHA titer 1024 was achieved after the $20^{\text {th }}$ passage. Later these high titer viruses were subjected to In Ovo antiviral assays.

\section{Anti-NDV activity from different extracts of Cholistani plants}

According to this experiment, the $n$-hexane extracts of all plants were effective in controlling NDV. The $n$-hexane extracts of A. aspera, S. baryosma, P. antidotale, $H$. salicornicum, O. esculentum, S. icolado, $S$. fruticosa, $H$. recurvum, N. procumbens were completely and equally effective (HA titer 0 ) against NDV. The extract of $S$. 
surattense was slightly less effective and it did not completely inhibit the growth of the virus (HA titer 16). The extract of $O$. compresssa was further less effective and it has reduced the HA titer at 64 . According to the results of ethyl acetate extracts of Cholistani plants, all extracts were effective in controlling NDV. The ethyl acetate extract of O. esculentum, $S$. icolados, A. aspera, $S$. baryosma, $P$. antidotale, $S$. surattense, $N$. procumbens, O. compresssa were completely effective and did not allow the virus to grow at all (HA titer 0 ). The extracts of H. salicornicum, S. fruticosa H. recurvum, were also effective but did not stop the complete growth of the virus (HA titer 8,8 and 32 respectively). In the case of $n$-butanol extracts of Cholistani plants were effective, but in varying degree. The extracts of $A$. aspera, $S$. baryosma, $P$. antidotale were first in order and they have completely inhibited the growth of the virus (HA titer 0 ). The extracts of O. esculentum, S. icolados, $H$. recurvum were second in order and HA titer was 2 in their cases. The extracts of $H$. salicornicum, S. surattense, N. procumbens, S. fruticosa, O. compresssa were third in order and HA titers were 8,16,16,32 and 32 respectively. The overall trend was $n$-hexane extracts $>$ ethyl acetate extracts $>n$-butanol extracts (Fig. 1). $\mathrm{IC}_{50}$ of each positive extract was calculated and reported in Table 1.

\section{Anti-AIV activity form different extracts of Cholistani plants}

The $n$-hexane extract of $P$. antidotale was completely effective (HA titer 0 ). The extracts of $H$. recurvum, O. compressa, $N$. procumbens, S. surattense were less effective and HA titers from these plants were $32,32,32$ and 512 respectively. The extracts of A. aspera, O. esculentum, $S$. baryosma S. fruticosa, H. salicornicum, $S$. icolados were almost ineffective (HA titer 1024 minimum and 2048 maximum). According to the results of ethyl acetate extracts of Cholistani plants, all extracts were not equally effective in controlling AIV. The extract of $A$. aspera was highly effective in controlling the growth of AIV (HA titer 0$)$. The extract of $O$. esculentum, O. compressa, $S$. baryosma, $H$. recurvum were less effective (HA titer 64, 256, 256 and 512 respectively). The extract of $S$. surattense, $N$. procumbens, $H$. salicornicum, $P$. antidotale, $S$. fruticosa, $S$. icolados were not effective in controlling the growth of AIV. Similarly, in the case of $n$-butanol extract, all plants were not equally effective. The extract of $N$. procumbens was

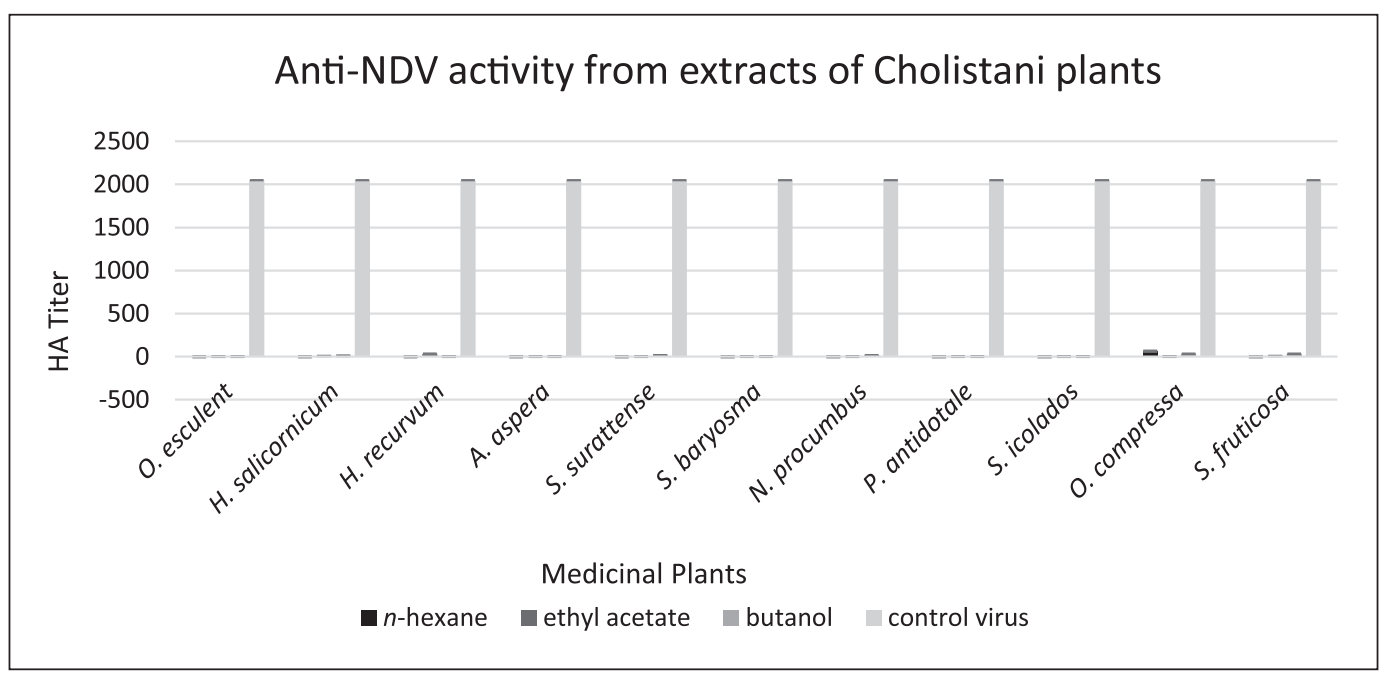

Figure 1. A: Anti-NDV activity from extracts of Cholistani plants.

$1^{\text {st }}$ bar of each column express the HA titer of $n$-hexane extract. $2^{\text {nd }}$ bar of each column presents the HA titer against ethyl acetate extract. $3^{\text {rd }}$ bar of each column shows the HA titer against $n$-butanol extract and $4^{\text {th }}$ bar of each column represents the HA titer of control virus. 
most effective and it has completely inhibited the growth of AIV (HA titer 0). The extracts of $S$. surattense, O. compressa, S. fruticosa, $S$. baryosma, O. esculentum were next in order and slightly less effective in controlling the growth of AIV (HA titer 8, 16, 16, 64 and 64 respectively). The extract of $H$. salicornicum, A. aspera, $P$ antidotale, $H$. recurvum, $S$. icolados were ineffective in controlling the growth of virus (HA titer 2048). The overall trend was n-butanol extracts $>n$-hexane extracts $>$ ethyl acetate extracts in controlling AIV H9N2 growth (Fig. 2). $\mathrm{IC}_{50}$ of each positive extract was calculated and reported in Table 1.

\section{Anti-IBV activity form different extracts of Cholistani plants}

According to this experiment, the $n$-hexane extract of $O$. esculentum, N. procumbus, A. aspera, S. baryosma were effective and completely active (HA titer 0) against IBV. The extract of $O$. compressa, $H$. recurvum, $P$. antidotale, $S$. fruticosa, $S$. icolados, $S$. surattense were less effective and their HA titers were 64 and 512 respectively. The extract of $H$. salicornicum was entirely ineffective (HA titer 2048). In the case of ethyl acetate extracts, some extracts were very effective like extracts of $O$. esculentum, $N$. procumbus, S. surattense, A. aspera, $S$. baryosma, $H$. salicornicum, $S$. icolados (HA titer 0). The extract of $P$. antidotale, $S$. fruticosa, O. compressa were moderately effective (HA titer 8 and 32 respectively) and extract of $H$. recurvum was absolutely ineffective. In the case of $n$-butanol extracts all plants were effective, but in varying order. The extracts of $A$. aspera, $S$. baryosma were very effective (HA titer 0 ) but extracts of O. compressa, O. esculentum, $H$. recurvum, $S$. surattense, $S$. icolados, $P$. antidotale, $N$. procumbus, $S$. fruticosa were moderately effective and HA titers were 8, 64, 128, 128 and 256 respectively and extract of $H$. salicornicum was completely ineffective. The overall trend against this virus was ethyl acetate extracts $>n$-hexane extracts $>$ $n$-butanol extracts (Fig. 3). $\mathrm{IC}_{50}$ of each positive extract was calculated and reported in Table 1.

\section{Anti-IBDV activity form different extracts of Cholistani plants}

According to this experiment, the $n$-hexane extract of all plants was ineffective in controlling IBDV expect $A$. aspera (IHA titer $64)$, which was moderately active. In the

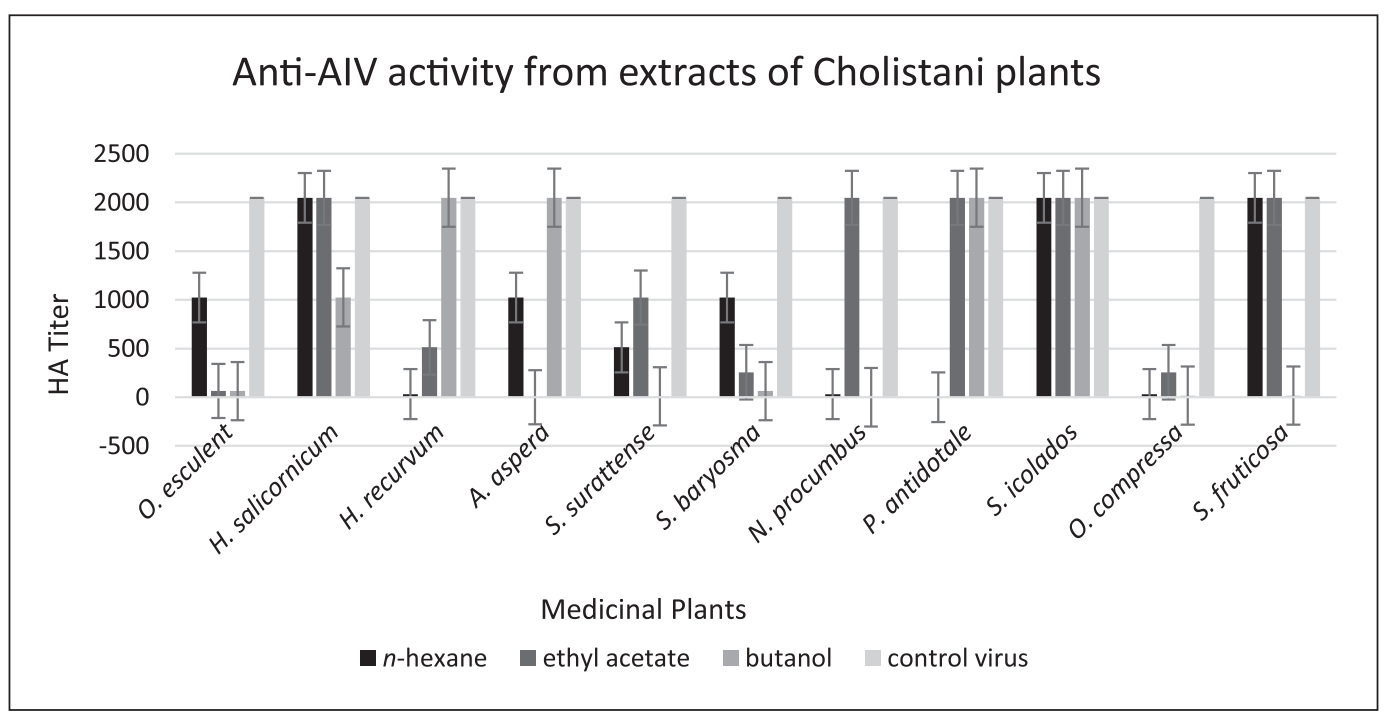

Figure 2. B: Anti-AIV activity from extracts of Cholistani plants.

$1^{\text {st }}$ bar of each column express the HA titer of $n$-hexane extract. $2^{\text {nd }}$ bar of each column presents the HA titer against ethyl acetate extract. $3^{\text {rd }}$ bar of each column shows the HA titer against $n$-butanol extract and $4^{\text {th }}$ bar of each column represents the HA titer of control virus. 


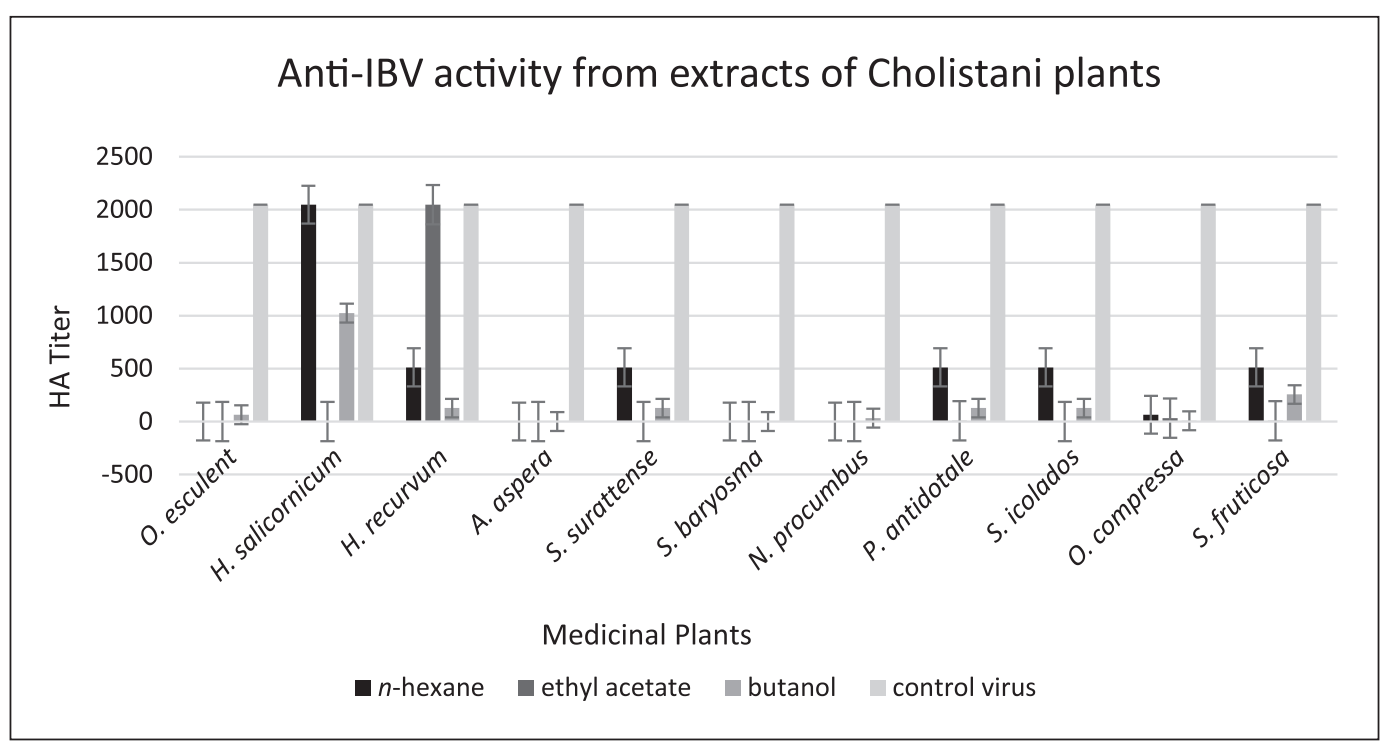

Figure 3. C: Anti-IBV activity from extracts of Cholistani plants.

$1^{\text {st }}$ bar of each column express the HA titer of $n$-hexane extract. $2^{\text {nd }}$ bar of each column presents the HA titer against ethyl acetate extract. $3^{\text {rd }}$ bar of each column shows the HA titer against butanol extract and $4^{\text {th }}$ bar of each column represents the HA titer of control virus.

case of ethyl acetate extracts, some extracts were effective in controlling IBDV like $O$. Compressa, $N$. procumbens and some were moderately effective like $P$. antidotale, $H$. recurvum, A. aspera (IHA titer 16, 16, 64, 64 and 64 respectively) and others were finally ineffective. In the case of $n$-butanol extracts, $N$. procumbens was completely effective (IHA titer 0) and extracts of O. Compressa, $S$. baryosma, $P$. antidotale, A. aspera, $S$. fruticosa were moderately effective (IHA titers 8, 16, 32, 32 and 32 respectively) and the rest of plant extracts were totally ineffective. The overall trend against IBDV was $n$-butanol extracts $>$ ethyl acetate extracts $>n$-hexane extracts (Fig. 4 ). $\mathrm{IC}_{50}$ value of each extract was calculated and reported in Table 1.

\section{DISCUSSION}

According to the World Health Organization (WHO), more than $70 \%$ of populations of developing countries still rely on traditional medicines to resolve their health issues (Rabe \& Van Staden, 2000). The use and importance of herbal medicines are on a continuous rise for the last decade (Knezevic et al., 2016). The use of traditional medicines and medicinal plants is embedded in the history of mankind. The extracts were originally done by crushing or squeezing or boiling herbal materials in water (Sujarwo, 2015). The plant-based products are more effective and work synergistically and provide less time for microbes to develop resistance against it (Solanki, 2010). Hundreds of plants and herbs have been reported with significantly high antimicrobial potentials. Some phytochemicals, including flavonoids, terpenoids, polyines, thiophenes, polyphenolics, lignans, sulphides, coumarins, saponins, furyl compounds, alkaloids, proteins, and peptides have been reported from different plants with antiviral potentials against different viruses (Jassim \& Naji, 2003; Shahzad et al., 2019). Most of these compounds are secondary metabolites of plants and they are not only effective against the virus but also bacteria and fungi (Gupta \& Chaphalkar, 2015). The other compounds like volatile essential oils from spices and herbal teas are also reported with antiviral activities (Jassim \& Naji, 2003). Typically 20$30 \%$ of plants from temperate regions have 


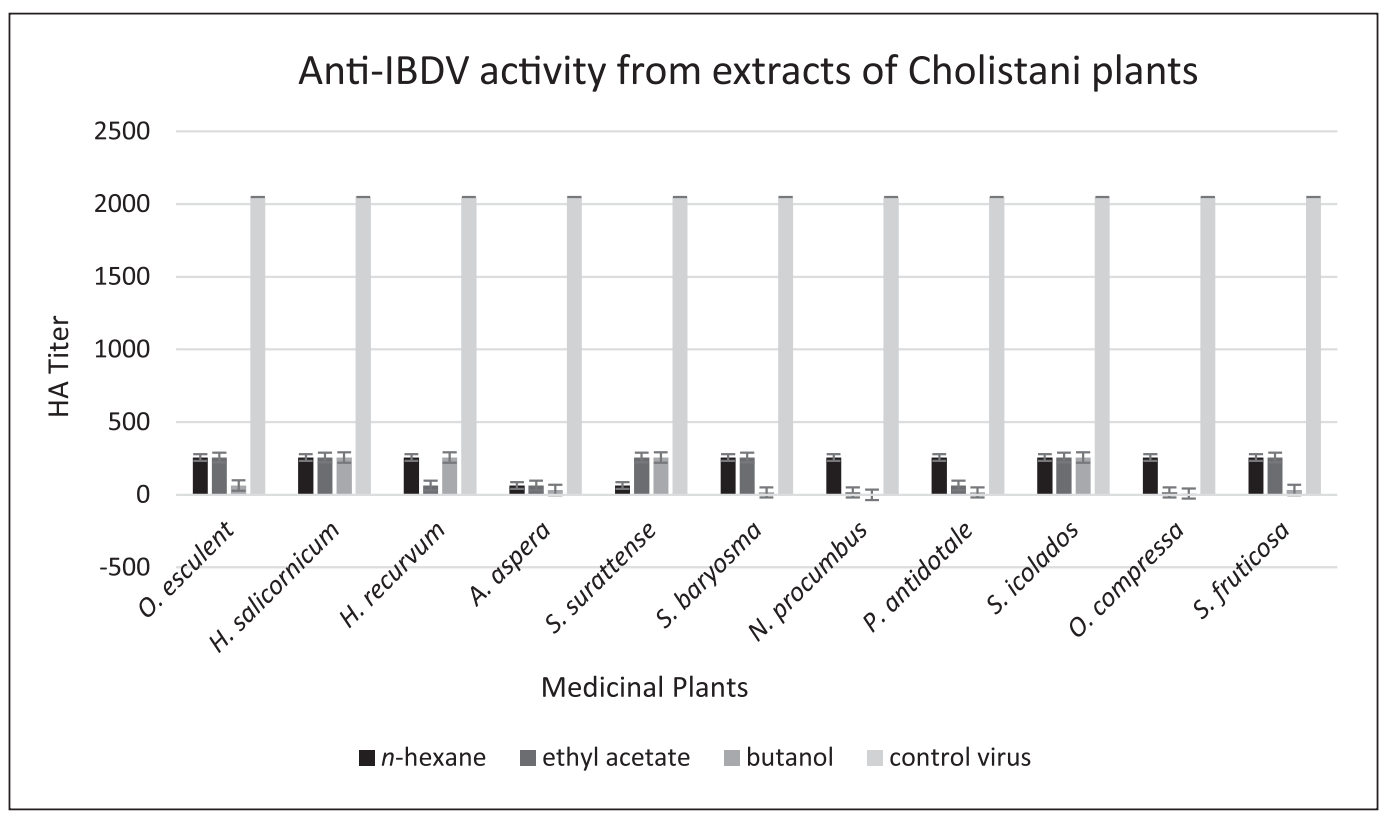

Figure 4. D: Anti-IBV activity from extracts of Cholistani plants.

$1^{\text {st }}$ bar of each column express the HA titer of $n$-hexane extract. $2^{\text {nd }}$ bar of each column presents the HA titer against ethyl acetate extract. $3^{\text {rd }}$ bar of each column shows the HA titer against $n$-butanol extract and $4^{\text {th }}$ bar of each column represents the HA titer of control virus.

been observed to possess antiviral activity. A large number of compounds of varied chemical structures isolated from medicinal plants have been shown to possess antiviral activity (Perez, 2003).

According to this study no. of selected Cholistani plants were found effective against common poultry viruses. In the case of Newcastle disease virus (NDV), strong antiNDV activities were reported from Cholistani plants. According to this study, 9 out of 11 $n$-hexane, 9 out of 11 ethyl acetate and 9 out of $11 n$-butanol extracts were positive against NDV. Very low values of $\mathrm{IC}_{50}$ of plants like A. aspera, S. baryosma, N. procumbus, $P$. antidotale, and many others depict the potential of the Cholistani plant against NDV. The results of this study are in accordance with already reported studies like (Rajbhandari et al., 2001) have reported antiviral activities from selected medicinal plants by In Ovo antiviral assays. (ElizondoGonzalez et al., 2012) have reported a plant based compound Fucoidan from $C$. Okamuranus against NDV. (Premnathan et al., 1992) has reported antiviral activity against NDV, vaccinia and $\mathrm{HBV}$ from methanol extracts of different seaweeds, sea grasses and of mangroves of the southeast coastal region of India. Similarly, in another study done by (Usha et al., 2012) aqueous, ethanol and methanol extracts of C. crista L. were tested against NDV. (Chollom et al., 2012) have reported anti-NDV activity from fruit pulp and leaf extracts of Momordic abalsamin through the cell line bases antiviral assay.

In the case of Avian Influenza Virus (AIV) H9N2, number of Cholistani plants were effective in different fractions. Total 4 out of $11 n$-hexane, 2 out of 11 ethyl acetate and 6 out of 11 n-butanol extracts were effective. Only O. compressa was effective in controlling AIV in all of its fractions, the rest of the plants were effective in one or two fractions. Similarly, the low $\mathrm{IC}_{50}$ value of these plants confirms the potential of Cholistani plants against AIV. The similar results are reported by other researchers like (Park, 2003) have reported anti AIV activity from methanol extracts of four Korean medicinal plants. (Lee et al., 2016; Shahzad 
et al., 2019) have reported anti AIV activity from n-hexane and ethyl acetate extracts of green tea. Studies done by (Droebner et al., 2017; Ehrhardt et al., 2007) have confirmed the antiviral effects of Proantho cyanidins derived from plants against AIV strains.

According to the results of this study, Cholistani plants are rich sources of anti-IBV agents and 5 out of $11 n$-hexane, 10 out of 11 ethyl acetate and 5 out of $11 n$-butanol extracts were positive against IBV. Overall 5 plants including $O$. esculent, $A$. aspera, $S$. baryosma, $N$. procumbus and O. compressa were completely effective through all of their extracts in controlling IBV even very low $\mathrm{IC}_{50}$ depict the potential of these plants against IBV. (Chen et al., 2014) have reported antiviral activity against IBV from ethanol extracts of $R$. rosea roots, $N$. sativa seeds, and S. snigra frui. (Ahmed et al., 2014; Musaddiq et al., 2020) have reported anti-IBV and IBDV activity from methanol extracts of Cholistani plants. In the case of Infectious Bursal Disease Virus (IBDV), $2 n$-hexane, 5 ethyl acetate and, $7 n$-butanol extracts were effective. Overall $A$. aspera was found very effective against IBDV through all of its extracts. The low $\mathrm{IC}_{50}$ values of extracts of this plant have highlighted its potential against IBDV. It is worth to mentioning that there is no know anti IBDV drug available in the market and this disease is known as AIDS of poultry. The number of studies are available, which have highlighted the use of medicinal plants against IBDV. (Pant et al., 2012) have reported anti IBDV activity from the hydro-alcohol extract of $W$. somnifera roots. (Ahmed et al., 2014) have reported anti IBDV activity from ethanol extracts of M. oleifera, P. emblicus, G. glabra, and E. jambolana through cell line based assay (Simoni et al., 2007) have tested number of medicinal plants from Brazilian flora against IBDV, herpes virus type I (BoHV-1) and avian reovirus. A total 8 out of 16 plants were effective against (BoHV-1) and avian reovirus but none of them was effective against IBDV. Anti-IBV and IBDV activity from methanol extracts of Cholistani plants. The mechanism of most of the antiviral compounds is needed to be determined yet (Aslam et al., 2016; Shahzad et al., 2019). Some researchers have anticipated the loss with the attachment of the virus to the host cell surface by antiviral agents, especially at the early stage of infection and some have suggested complete or partial inhibition of essential enzymes of viruses. Some other researchers have suggested the protein or polypeptide nature of antiviral compounds (Bajpai \& Chandra, 1990).

Vanden et al. (1986) have reported that there will be an increasing need for substances with antiviral activity soon because the current treatments of viral infections are often unsatisfactory and limited. Mutation in viruses and resistance to the existing antiviral agents will readily arise upon treatment. These compounds could be extracted from higher plants. Many of these plants have been used historically to treat diseases now known to be of viral origin (Louis \& Balakrishnan, 1996; Tahir et al., 2019). The author has already published the effect of the methanol extract of these plants against the same poultry viruses (Aslam et al., 2016; Shahzad et al., 2019; Musaddiq et al., 2020).

Acknowledgments. We are thankful to Director Government poultry farm Bahawalpur for providing embryonated eggs. We acknowledge the services of Mr. Izhar, Lab attendant at Biochemistry and Molecular Biology Lab, UCVAS, The Islamia University Bahawalpur to being a helping hand and ensure the supply of embryonated eggs at the lab. We are thankful to Mr. Irfan Saeed for facilitating in HA assay and providing embryonated eggs.

\section{Declaration of interest}

All authors are duly informed and gone through this manuscript. There is no conflict of interest in this paper.

\section{REFERENCES}

Abad, M.J., Bermejo, P., Villar, A., Sanchez Palomino, S. \& Carrasco, L. (1997). Antiviral activity of medicinal plant extracts. Phytotherapy Research 11: 198-202. 
Ahmad, W., Ejaz, S., Anwar, K. \& Ashraf, M. (2014). Exploration of the in vitro cytotoxic and antiviral activities of different medicinal plants against infectious bursal disease (IBD) virus. Central Europe Journal of Biology 9: 531-42.

Arunkumar, S. \& Muthuselvam, M. (2009). Analysis of phytochemical constituents and antimicrobial activities of Aloe vera L. against clinical pathogens. Wayamba Journal of Animal Science 5: 572-6.

Aslam, A., Shahzad, M.I., Parveen, S., Ashraf, H., Naz, N., Zehra, S.S., Kamran, Z., Qayyum, A. \& Mukhtar, M. (2016). Evaluation of antiviral potential of different cholistani plants against infectious bursal disease and infectious bronchitis virus. Pakistan Veterinary Journal 36: 302-306.

Bajpai, S.K. \& Chandra, K. (1990). Studies on the antiviral properties of plants with special reference to Zingiber capitatum. Fitoterapia 61: 3-8.

Chen, C., Zuckerman, D.M., Brantley, S., Sharpe, M., Childress, K., Hoiczyk, E. \& Pendleton, A.R. (2014). Sambucus nigra extracts inhibit infectious bronchitis virus at an early point during replication. Veterinary Research 10: 1-12.

Chollom, S.C., Agada, G.O., Bot, D.Y., Okolo, M.O., Dantong, D.D., Choji, T.P., Echeonwu, B.C., Bigwan, E.I., Lokason, S. \& Banwat, E. (2012). Phytochemical analysis and antiviral potential of aqueous leaf extract of Psidium guajava against newcastle disease virus In Ovo. International Journal of Applied Pharmaceutics 10: 45-49.

Droebner, K., Ehrhardt, C., Poetter, A., Ludwig, S. \& Planz, O. (2017). CYSTUS052, a polyphenol-rich plant extract, exerts anti-influenza virus activity in mice. Antiviral Research 76: 1-10.

Ehrhardt, C., Hrincius, E.R., Korte, V., Mazur, I., Droebner, K., Poetter, A., Dreschers, S., Schmolke, M., Planz, O. \& Ludwig, S. (2007). A polyphenol rich plant extract, CYSTUS052, exerts anti influenza virus activity in cell culture without toxic side effects or the tendency to induce viral resistance. Antiviral Research 76: 38-47.
Elizondo-Gonzalez, R., Cruz-Suarez, L.E., Ricque-Marie, D., Mendoza-Gamboa, E., Rodriguez-Padilla, C. \& Trejo-Avila, L.M. (2012). In vitro characterization of the antiviral activity of fucoidan from Cladosiphon okamuranus against Newcastle Disease Virus. Virology Journal 9: 307-312.

Giasuddin, M., Haque, M.E., Kamal, A.H., Islam, M.R., Jahangir, A., Chowdhury, E.H., Taimur, M.J.F.A. \& Rahman, M.H. (2012). Outbreak evaluation of highly pathogenic avian influenza in Bangladesh. Bangladesh Journal of Livestock Research 19: 44-49.

Gupta, A. \& Chaphalkar, S.R. (2015). Inhibitory Potential of Aqueous Leaves Extract of Mesua ferrea and Mimusops elengi on Antigen Specific Immune Response using Human Whole Blood. Asian Journal of Research in Medical and Pharmaceutical Sciences 5: 22-26.

Hussain, M.A. \& Gorsi, M.S. (2004). Antimicrobial activity of Nerium oleander Linn. Asian Journal of Plant Science 3: $177-80$.

Jassim, S.A. \& Naji, M.A. (2003). Novel antiviral agents: a medicinal plant perspective. Journal of Applied Microbiology 95: 412-27.

Joshi, M. (2013). In vitro evaluation of antimicrobial activity and phytochemical analysis of Calotropis procera, Eichhornia crassepie and Datura innoxia leaves. Asian Journal of Pharmaceutical and Clinical Research 6: 25-28.

Kitazato, K., Wang, Y. \& Kobayashi, N. (2007). Viral infectious disease and natural products with antiviral activity. Drug Discoveries \& Therapeutics 1: 14-22.

Knezevic, P., Aleksic, V., Simin, N., Svircev, E., Petrovic, A. \& Mimica-Dukic, N. (2016). Antimicrobial activity of Eucalyptus camaldulensis essential oils and their interactions with conventional antimicrobial agents against multi-drug resistant Acinetobacter baumannii. Journal of Ethnopharmacology 178: 125136. 
Lee, D.H., Fusaro, A., Song, C.S., Suarez, D.L. \& Swayne, D.E. (2016). Poultry vaccination directed evolution of H9N2 low pathogenicity avian influenza viruses in Korea. Journal of Virology 488: 225-231.

Lee, H.J., Lee, Y.N., Youn, H.N., Lee, D.H., Kwak, J.H., Seong, B.L., Lee, J.B., Park, S.Y., Choi, I.S. \& Song, C.S. (2012). Anti-influenza virus activity of green tea by-products in vitro and efficacy against influenza virus infection in chickens. Poultry Science 9: 66-73.

Li, J., Gu, M. \& Liu, D. (2016). Phylogenetic and biological characterization of three K1203 (H5N8)-like avian influenza A virus reassortants in China in 2014. Archives of Virology 161: 289-302.

Louis, V. \& Balakrishnan, S. (1996). Effect of application of selected medicinal plant extracts on the incidence of pumpkin mosaic virus. Indian Phytopathology 49: 373-377.

Musaddiq, S., Shahzad, M.I., Farzana, F., Mehwish, T., Atia, I., Abida, A. \& Samina, A. (2020). Thiazolidines; Potential Antiviral Agents against Avian Influenza and Infectious Bronchitis Viruses. Veterinary Research Forum. 1808-2211 (Accepted).

Nostro, A., Germano, M.P., D'angelo, V., Marino, A. \& Cannatelli, M.A. (2000). Extraction methods and bioautography for evaluation of medicinal plant antimicrobial activity. Letters in Applied Microbiology 30: 379-384.

Okwor, E.C., Eze, D.C. \& Okonkwo, K. (2011). Serum Antibody Levels against Infectious Bursal Disease Virus in Nigerian Village Chickens. Pakistan Veterinary Journal 32: 286-287.

Pant, M., Ambwani, T. \& Umapathi, V. (2012). Antiviral activity of Ashwa gandha extract on infectious bursal disease virus replication. Indian Journal of Science and Technology 5: 2750-2751.

Park, K.J. (2003). Evaluation of in vitro antiviral activity in methanol extracts against inuenza virus type A from Korean medicinal plants. Phytotherapy Research 17: 1059-1763.
Perez, R.M. (2003). Antiviral activity of compounds isolated from plants. Pharmaceutical Biology 41: 107-157.

Premnathan, M., Chandra, K., Bajpai, S.K. \& Kathiresan, K. (1992). A survey of some Indian marine plants for antiviral activity. Botanica Marina 35: 321-324.

Rajbhandari, M., Wegner, U., Jülich, M., Schoepke, T. \& Mentel, R. (2001). Screening of Nepalese medicinal plants for antiviral activity. Journal of Ethnopharmacology 74: 251-255.

Rasool, A., Xiao, T., Baig, Z.T., Masood, S., Mostofa, K.M. \& Iqbal, M. (2015). Cooccurrence of arsenic and fluoride in the groundwater of Punjab, Pakistan: source discrimination and health risk assessment. Environmental Science and Pollution Research 22: 19729-19746.

Rabe, T. \& Van Staden, J. (2000). Isolation of an antibacterial sesquiterpenoid from Warburgia salutaris. Journal of Ethnopharmacology 73: 171-174.

Roeder, E., Wiedenfeld, H. \& Edgar, J.A. (2015). Pyrrolizidine alkaloids in medicinal plants from North America. International Journal of Pharmacy 70: 357-367.

Sá e Silva, M., Susta, L., Moresco, K. \& Swayne, D.E. (2016). Vaccination of chickens decreased Newcastle disease virus contamination in eggs. Avian Pathoogyl 45: 38-45.

Steel, R.G., Torrie, J.H. \& Dickey, D.A. (1997). Principles and Procedures of Statistics: A Biometrical Approach, 3rd edition. McGraw Hill Co. New York, USA.

Seeff, L.B., Bonkovsky, H.L., Navarro, V.J. \& Wang, G. (2015). Herbal products and the liver: a review of adverse effects and mechanisms. Gastroenterology 148: 517-532.

Shahzad, M.I., Ashraf, H., Arshad, M., Parveen, S., Aslam, A., Naz, N. \& Mukhtar, M. (2019). Study of Antiviral Potential of Cholistani Plants against New Castle Disease Virus. Pakistan Journal of Zoology 51: 395-398. 
Simoni, I.C., Manha, A.P., Sciessere, L., Hoe, V.M., Takinami, V.H. \& Fernandes, M.J. (2001). Evaluation of the antiviral activity of Brazilian cerrado plants against animal viruses. Vírus Reviews \& Research 12: 25-31.

Singh, S.N. (2011). Foot and Mouth Disease control strategies global frame work. International Journal of Life Sciences \& Pharma Research 1: 63-70.

Solanki, R. (2014). Some medicinal plants with antibacterial activity. International Journal of Comprehensive Pharmacy 4: $1-4$.
Sujarwo, W., Keim, A.P., Savo, V., Guarrera, P.M. \& Caneva, G. (2015). Ethnobotanical study of Loloh: Traditional herbal drinks from Bali (Indonesia). Journal of Ethnopharmacology 169: 34-48.

Tahir, T., Ashfaq, M., Asghar, H., Shahzad, M.I., Tabassum, R. \& Ashfaq, A. (2019). Medicinal Importance of Azo and Hippuric Acid Derivatives. MiniReviews in Medicinal Chemistry 19: 708-719.

Vanden Berghe, D.A., Vhetinck, A.J. \& L. Van Hoof, L. (1986). Plant products as potential antiviral agents. Bulletin de l'Institut Pasteur 84: 101-147. 